\title{
Gender disparities in pulmonary hypertension at a tertiary centre in Cameroon
}

\author{
L N Aminde, ${ }^{1,2,3} \mathrm{MD}$; A Dzudie,${ }^{2,3,4} \mathrm{MD}$, PhD, FESC; A P Kengne, ${ }^{3,5,6} \mathrm{MD}$, PhD; J Ndjebet, ${ }^{7} \mathrm{MD} ; \mathbf{S}$ Mapoh, ${ }^{2,3} \mathrm{MD} ; \mathbf{X}$ Kuelang, ${ }^{8} \mathrm{MD}$; \\ F Kamdem, ${ }^{2,9} \mathrm{MD}$; B H Mbatchou Ngahane, ${ }^{9,10} \mathrm{MD}$; M-S Doualla, ${ }^{11,12} \mathrm{MD}$; K B Ngu, ${ }^{12,13} \mathrm{MD}, \mathrm{FRCP}, \mathrm{FESC}$; K Sliwa, ${ }^{5,13} \mathrm{MD}, \mathrm{PhD}, \mathrm{FESC}$; \\ F Thienemann, ${ }^{5,14,15} \mathrm{MD}, \mathrm{MScIH}, \mathrm{DTMPH}$ \\ ${ }^{1}$ School of Public Health, Faculty of Medicine, University of Queensland, Brisbane, Australia \\ 2 Cardiology Unit, Department of Internal Medicine, General Hospital Douala, Cameroon \\ ${ }^{3}$ Clinical Research Education, Networking and Consultancy, Douala, Cameroon \\ ${ }^{4}$ Soweto Research Group, Department of Medicine, Faculty of Health Sciences, University of the Witwatersrand, Johannesburg, South Africa \\ ${ }^{5}$ Department of Medicine, Faculty of Health Sciences, University of Cape Town, South Africa \\ ${ }^{6}$ Non-Communicable Diseases Research Unit, South African Medical Research Council, Cape Town, South Africa \\ 7 Douala Cardiovascular Centre of Bonapriso, Cameroon \\ 8 Universite de Montagne, Bangante, Cameroon \\ ${ }^{9}$ Faculty of Medicine and Pharmaceutical Sciences, University of Douala, Cameroon \\ ${ }^{10}$ Pulmonology Unit, Department of Internal Medicine, General Hospital Douala, Cameroon \\ ${ }^{11}$ Rheumatology Unit, Department of Internal Medicine, General Hospital Douala, Cameroon \\ ${ }^{12}$ Faculty of Medicine and Biomedical Sciences, University of Yaoundé I, Cameroon \\ ${ }^{13}$ Hatter Institute for Cardiovascular Research in Africa, University of Cape Town, South Africa \\ ${ }^{14}$ Institute of Infectious Diseases and Molecular Medicine, Faculty of Health Sciences, University of Cape Town, South Africa \\ ${ }^{15}$ Department of Internal Medicine, University Hospital Zürich, Switzerland
}

Corresponding author: LN Aminde (l.aminde@uq.edu.au,amindeln@gmail.com)

Background. Pulmonary hypertension $(\mathrm{PH})$ is a potent cause of heart failure and has been little investigated in the African setting. Objective. To investigate the effects of gender on the clinical presentation, echocardiographic features and outcomes of patients with $\mathrm{PH}$ in Douala, Cameroon.

Methods. A prospective cohort study was conducted from March 2012 to December 2013 as part of the Pan African Pulmonary Hypertension Cohort study. PH was diagnosed by echocardiography and defined as a right ventricular systolic pressure $>35 \mathrm{mmHg}$ in the absence of acute right heart failure. Patients were followed up for a maximum of 12 months for primary endpoint mortality.

Results. In total, 130 patients with PH were recruited; 71 (54.6\%) were women. The median age was 59.2 years for men and 58.3 years for women $(p=0.76)$. Active smoking and alcohol use were more frequent in men than women (both $p<0.001)$, but women had greater exposure to indoor cooking fumes than men $(p<0.001)$. Previous tuberculosis infection $(11.3 \%$ v. $1.7 \%)$ and S3 gallop rhythm $(30.9 \%$ v. $11.9 \%)$ were more common in women (both $p<0.03)$. Women had a significantly higher mean systolic blood pressure $(134 \mathrm{mmHg}$ v. $125 \mathrm{mmHg} ;=0.04)$ and pulse pressure $(53.8 \mathrm{mmHg}$ v. $44.9 \mathrm{mmHg} ; p=0.01)$ and a lower mean haemoglobin concentration $(10.4 \mathrm{~g} / \mathrm{dL} \mathrm{v} .12 .4 \mathrm{~g} / \mathrm{dL} ; p<0.05)$ compared with men. Echocardiographic left ventricular (LV) systolic dysfunction was more frequent in men: mean LV ejection fraction $42.6 \%$ v. $51.5 \%(p=0.01)$ and mean fractional shortening $21.4 \%$ v. $28.6 \%(p=0.01)$. The overall mortality rate was $20.3 \%$, and rates were similar in the two groups (Kaplan-Meier log rank $1.1 ; p=0.30$ ).

Conclusions. Despite differences in baseline characteristics including cardiovascular risk factors, mortality rates on follow-up were similar in men and women in this study. However, these different baseline characteristics probably suggest differences in the pathogenesis of PH in men and women in our setting that need further investigation.

S Afr Med J 2017;107(10):892-899. DOI:10.7196/SAMJ.2017.v107i10.12321

Pulmonary hypertension $(\mathrm{PH})$ describes a group of disorders resulting from an increase in pulmonary vascular resistance, pulmonary blood flow, pulmonary venous pressure, or a combination of these. ${ }^{[1]} \mathrm{PH}$ is defined as an increase in mean pulmonary arterial pressure of $\geq 25 \mathrm{mmHg}$ at rest, assessed by right heart catheterisation (RHC). ${ }^{[2]}$ Based on shared pathological and haemodynamic characteristics and therapeutic approaches, $\mathrm{PH}$ is currently classified into five subtypes, namely $\mathrm{PH}$ groups $1-5 .^{[3]}$ Epidemiological studies from Western countries suggest that the prevalence of $\mathrm{PH}$ among African Americans is higher than that among Caucasians, ${ }^{[4]}$ while in a community-based echocardiographic cohort study in Armadale,
Australia, a prevalence of $9.1 \%$ and high mortality were observed. ${ }^{[5]}$ In sub-Saharan Africa (SSA) however, there is some evidence that, based on the high prevalence of risk factors such as hypertension and other endemic communicable diseases such as schistosomiasis and $\mathrm{HIV}$ infection, the prevalence of $\mathrm{PH}$ may be higher than in Western countries. ${ }^{[6]}$ Moreover, it has been suggested that left heart disease is the most frequent cause of $\mathrm{PH}$ worldwide. ${ }^{[7,8]}$

$\mathrm{PH}$ is a disease with devastating effects on quality of life and life expectancy, and is a potent cause of heart failure (HF) in general. ${ }^{[7,9-12]}$ Indeed, one autopsy study from South Africa identified $\mathrm{PH}$ as one of the commonest causes of death, accounting for 
$31 \%$ of all cardiovascular deaths. ${ }^{[13]}$ The Pan African Pulmonary Hypertension Cohort (PAPUCO) study was established to investigate the epidemiology, causes and natural history of $\mathrm{PH}$ in Africa. ${ }^{[1,15]}$ While the epidemiology of PH in Africa remains largely unknown, it is important to highlight the fact that clinical features of $\mathrm{PH}$ are often subtle and nonspecific, especially in the early stages, and may mimic other diseases, so that $\mathrm{PH}$ remains undiagnosed. Risk factors, epidemiology, clinical characteristics and outcomes of HF have gender variations that have been described among Caucasians. ${ }^{[16-18]}$ Recent data from the largest HF registry in SSA suggest that HF was more likely to have been caused by rheumatic heart disease in women and conventional modifiable cardiovascular risk factors in men, although outcomes appeared to be similar. ${ }^{[19]}$ The PAPUCO study presents a broad picture of $\mathrm{PH}$ in Africa, ${ }^{[15]}$ but country-specific data on gender differences in the characteristics and outcomes of $\mathrm{PH}$ in Africa are still lacking.

\section{Objective}

To investigate gender differences in clinical characteristics, echocardiographic findings and outcomes in a cohort of patients with PH in Douala, Cameroon.

\section{Methods \\ Study design and setting}

The PAPUCO study design has been described in great detail, ${ }^{[14]}$ and was registered on ClinicalTrials.gov (NCT02265887). In short, PAPUCO was a prospective pan-African multicentre cohort study of patients newly diagnosed with $\mathrm{PH}$ involving 12 specialist centres in SSA including Cameroon. The registry adhered to the Strengthening the Reporting of Observational Studies in Epidemiology (STROBE) guidelines for reporting observational outcomes.

\section{Eligibility}

Through convenient sampling, all adult patients ( $\geq 18$ years of age) who presented to the PAPUCO centre in Douala, Cameroon, with newly diagnosed $\mathrm{PH}$ were invited to take part in the study.

\section{Diagnosis of PH}

Diagnosis of $\mathrm{PH}$ was based on echocardiographic measurement of the right ventricular systolic pressure (RVSP) in the absence of acute right HF, reflecting pulmonary artery systolic pressure in the absence of pulmonary artery stenosis. The RVSP was obtained by measuring the tricuspid regurgitant jet velocity via a pulsed Doppler study of the tricuspid valve. The gradient between right atrium (RA) and right ventricle (RV) was obtained using the simplified Bernoulli equation

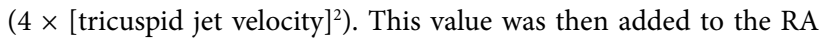
pressure (fixed value from 5 to $20 \mathrm{mmHg}$ estimated by measuring the inferior vena cava size and its change with spontaneous respiration during echocardiography) for RVSP. A value of $>35 \mathrm{mmHg}$ was considered PH. Details of the echocardiographic assessment have been described previously. ${ }^{[14]}$

\section{Data collection and study procedures}

Patients were interviewed and examined and data were entered on an electronic case report form. ${ }^{[14]}$ General and clinical characteristics included age, sex and risk factors for cardiovascular disease (CVD). A family history of CVD was defined as a documented family history of CVD; hypertension as a systolic (diastolic) blood pressure of $\geq 140$ (90) $\mathrm{mmHg}$, a documented history of hypertension or prescribed antihypertensive medication; presence of diabetes as a fasting blood glucose level of $\geq 7 \mathrm{mmol} / \mathrm{L}$, a documented history of diabetes or prescribed blood sugar-lowering agents; smoking as never having smoked, being an ex-smoker (if the patient had smoked for at least 3 years in the past, but had stopped at time of presentation) or being a current smoker (patients who smoked at least one cigarette per day at the time of presentation); and alcohol abuse as intake of either more than three (two for women) standard glasses of wine per day or more than ten (five for women) local beers (one local beer contains $28 \mathrm{~g}$ of alcohol) per week. The presence of symptoms (dyspnoea, fatigue, cough, palpitation) and signs on physical examination (distended jugular vein, pedal oedema, ascites, S3 gallop, P2 sound) was ascertained. The 6-minute walk test was also performed and the distance covered recorded in patients who had no contraindications. Patients underwent 12-lead electrocardiography, and standard blood results were obtained.

\section{Follow-up and outcome assessment}

From the time of recruitment, patients were followed up for 12 months. During the follow-up visit or interview, conducted either in person or via telephone calls, patients and their relatives were questioned about the number of hospitalisations since recruitment (if patients were alive); if they were dead, the time lapse from recruitment to death was recorded.

\section{Data and statistical analysis}

Data were analysed using the Statistical Package for the Social Sciences IBM statistical software version 20 for Windows (SPSS Inc., USA). Categorical variables were summarised using frequencies and proportions, while continuous variables were summarised using means and standard deviations or medians with 25th and 75th percentiles. Group comparisons used $\chi^{2}$ and Fisher's exact (where applicable) tests for categorical variables and the independentsamples $t$-test for continuous variables. The Kaplan-Meier estimator was used to assess the risk of death during follow-up, with group comparisons based on the log-rank test. The Cox proportional hazard model was used to further investigate the differential effect of gender on mortality. Statistical significance was set at $p<0.05$.

\section{Ethical considerations}

Approval was obtained from the Institutional Review Board of the Faculty of Health Sciences, University of Buea (ref. no. 2013/0080/ UB/FHS/IRB) and Douala General Hospital, Cameroon (ref. no. $179 \mathrm{AR} / \mathrm{MINSANTE} / \mathrm{HGD} / \mathrm{DM} / 12 / 12$ ) as well as from the National Ethics Committee (ref. no. 2013/11/363/L/CNERSH/SP). The PAPUCO study was approved by the University of Cape Town's Human Research Ethics Committee (ref. no. 241/2011). The study adhered to the Declaration of Helsinki and all participants provided informed written consent prior to participation.

\section{Results \\ Sociodemographic characteristics, risk factor profile and clinical findings}

During the study period, 1855 patients underwent echocardiographic examination. Of these, 130 (7.0\%) had an RVSP $>35 \mathrm{mmHg}$ and were included in the study. All were of black African descent, and 71 (54.6\%) were women. Table 1 summarises the baseline sociodemographic characteristics, risk factor profile and clinical findings of the cohort on a gender-specific basis. The mean age of the patients was 59 years, with no difference between men and women $(p=0.76)$. Men were more likely to be in the age group 55 - 64 years, while the majority of women were aged $\geq 75$ years. Fig. 1 depicts the age distribution of the study population according to gender. Cardiovascular risk factors 


\begin{tabular}{|c|c|c|c|c|}
\hline Variables & $\begin{array}{l}\text { Males } \\
(N=59)\end{array}$ & $\begin{array}{l}\text { Females } \\
(N=71)\end{array}$ & $\begin{array}{l}\text { Total } \\
(N=130)\end{array}$ & $p$-value* \\
\hline Age (yr), mean (SD) & $59.2(16.1)$ & $58.3(18.9)$ & $58.7(17.7)$ & 0.760 \\
\hline Family history of cardiovascular disease, $n$ (\%) & $29(49.2)$ & $37(52.1)$ & $66(50.8)$ & 0.724 \\
\hline Hypertension, $n(\%)$ & $33(55.9)$ & $37(52.1)$ & $70(53.8)$ & 0.601 \\
\hline Diabetes, $n(\%)$ & $9(15.3)$ & $10(14.1)$ & $19(14.6)$ & 0.503 \\
\hline Hypercholesterolaemia, $n$ (\%) & $10(16.9)$ & $10(14.1)$ & $20(15.4)$ & 0.630 \\
\hline Deep-vein thrombosis, $n(\%)$ & $3(5.1)$ & $2(2.8)$ & $5(3.8)$ & 0.655 \\
\hline Pulmonary embolism, $n$ (\%) & $3(5.1)$ & $3(4.2)$ & $6(4.6)$ & 0.565 \\
\hline Chronic lung disease, $n$ (\%) & $3(5.1)$ & $7(9.9)$ & $10(7.7)$ & 0.331 \\
\hline Exposure to indoor smoke, $n(\%)$ & $2(3.4)$ & $26(36.6)$ & $28(21.5)$ & $<0.001^{\dagger}$ \\
\hline Smoking, $n(\%)$ & & & & $<0.01^{\dagger}$ \\
\hline Current & $4(6.8)$ & $3(4.2)$ & $7(5.4)$ & \\
\hline Former & $15(25.4)$ & $5(7.0)$ & $20(15.4)$ & \\
\hline Never & $40(67.8)$ & $63(88.7)$ & $103(79.2)$ & \\
\hline Alcohol abuse, $n(\%)$ & $26(44.1)$ & $10(14.1)$ & $36(27.7)$ & $<0.0001^{\dagger}$ \\
\hline HIV-positive, $n$ (\%) & $1(1.7)$ & $1(1.4)$ & $2(1.5)$ & 1 \\
\hline Previous TB infection, $n(\%)$ & $1(1.7)$ & $8(11.3)$ & $9(6.9)$ & $0.031^{\dagger}$ \\
\hline NYHA class, $n(\%)$ & & & & 0.932 \\
\hline I & $1(1.7)$ & $2(2.8)$ & $3(2.3)$ & \\
\hline II & $14(23.7)$ & $19(26.8)$ & $33(25.4)$ & \\
\hline III & $25(42.4)$ & $27(38.0)$ & $52(40.0)$ & \\
\hline IV & $19(32.2)$ & $23(32.4)$ & $42(32.3)$ & \\
\hline Systolic murmur, $n(\%)$ & $23(38.9)$ & $26(36.6)$ & $49(37.7)$ & 0.718 \\
\hline Diastolic murmur, $n$ (\%) & $1(1.7)$ & $2(2.8)$ & $3(2.3)$ & 1 \\
\hline S3 gallop, $n(\%)$ & $7(11.9)$ & $22(30.9)$ & $29(22.3)$ & $0.011^{\dagger}$ \\
\hline Loud pulmonic P2, $n(\%)$ & $11(18.6)$ & $9(12.7)$ & $20(15.4)$ & 0.330 \\
\hline BMI $\left(\mathrm{kg} / \mathrm{m}^{2}\right)$, mean $(\mathrm{SD})$ & $24.9(5.0)$ & $25.6(7.3)$ & $25.3(6.3)$ & 0.599 \\
\hline Systolic BP (mmHg), mean (SD) & $125.0(23.1)$ & $134.2(28.6)$ & $130.0(26.5)$ & $0.041^{\dagger}$ \\
\hline Diastolic BP (mmHg), mean (SD) & $80.1(16.8)$ & $80.3(15.0)$ & $80.2(15.8)$ & 0.939 \\
\hline Pulse pressure (mmHg), mean (SD) & $44.9(14.6)$ & $53.9(22.4)$ & $49.8(19.7)$ & $0.012^{\dagger}$ \\
\hline Pulse at rest (bpm), mean (SD) & $87.5(17.8)$ & $83.3(20.4)$ & $85.2(19.2)$ & 0.223 \\
\hline Pulse oximetry (\%), mean (SD) & $95.3(4.3)$ & $96.4(2.6)$ & $96.0(3.3)$ & 0.250 \\
\hline Respiratory rate (breaths/min), mean (SD) & $26.9(9.1)$ & $25.4(7.1)$ & $26.1(8.1)$ & 0.318 \\
\hline 6-minute walk distance (m), mean (SD) & $266.0(168.7)$ & $250.7(112.7)$ & $258.3(141.8)$ & 0.699 \\
\hline
\end{tabular}

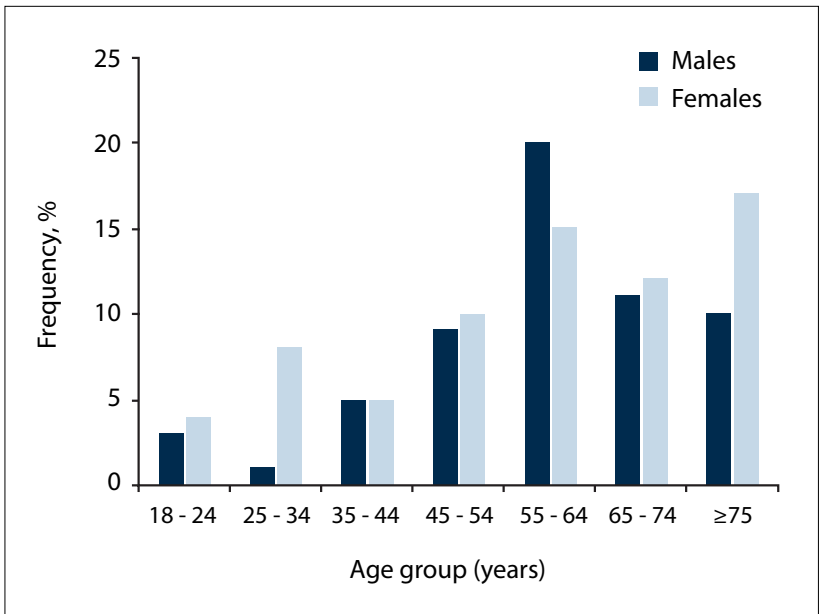

Fig. 1. Age distribution of patients with pulmonary hypertension according to gender in Douala, Cameroon, 2014. were prevalent in our cohort, hypertension ( $55.9 \%$ v. $52.1 \%$ ), diabetes $(15.3 \%$ v. $14.1 \%)$ and hypercholesterolaemia (16.9\% v. $14.1 \%)$ being similarly distributed between men and women. Alcohol abuse (44.1\% v. $14.1 \%)$ and current or previous smoking $(32.2 \%$ v. $11.2 \%)$ were significantly more common in men (both $p<0.01$ ), while exposure to indoor cooking fumes (36.6\% v. $3.4 \%)$ and previous tuberculosis (TB) infection $(11.3 \%$ v. $1.7 \%)$ were more common in women (both $p<0.03)$. At presentation, similar proportions of men and women were in New York Heart Association (NYHA) classes III and IV (74.6\% v. 70.4\%), although S3 gallop $(30.9 \%$ v. $11.9 \%$; $p=0.011)$ was more common in women. Mean systolic blood pressure $(134 \mathrm{mmHg}$ v. $125 \mathrm{mmHg}$; $p=0.041)$ and mean pulse pressure $(53.9 \mathrm{mmHg}$ v. $44.9 \mathrm{mmHg} ; p=0.01)$ were also significantly higher in women than in men.

\section{Electrocardiographic, laboratory and echocardiographic findings}

Table 2 summarises electrocardiographic and laboratory findings at presentation. No gender-specific differences were identified on 
Table 2. Baseline electrocardiographic and laboratory characteristics of patients with pulmonary hypertension in Douala, Cameroon, 2014

\begin{tabular}{|c|c|c|c|c|}
\hline Variables & $\begin{array}{l}\text { Males } \\
(N=59)\end{array}$ & $\begin{array}{l}\text { Females } \\
(N=71)\end{array}$ & $\begin{array}{l}\text { Total } \\
(N=130)\end{array}$ & $p$-value ${ }^{*}$ \\
\hline \multicolumn{5}{|l|}{ Electrocardiographic findings, $n(\%)$} \\
\hline Atrial fibrillation & $16(27.1)$ & $19(26.8)$ & $35(26.9)$ & 0.848 \\
\hline Normal sinus rhythm & $15(25.4)$ & $22(30.9)$ & $37(28.5)$ & 0.320 \\
\hline AV block type I & $8(13.5)$ & $9(12.7)$ & $17(13.1)$ & 1 \\
\hline AV block type III & $1(1.7)$ & $2(2.8)$ & $3(2.3)$ & 1 \\
\hline Sinus tachycardia & $21(35.6)$ & $16(22.5)$ & $37(28.5)$ & 0.231 \\
\hline RV hypertrophy & $6(10.2)$ & $6(8.4)$ & $12(9.2)$ & 1 \\
\hline LV hypertrophy & $13(22.0)$ & $11(15.5)$ & $24(18.5)$ & 0.645 \\
\hline \multicolumn{5}{|l|}{ Laboratory findings, mean (SD) } \\
\hline Haemoglobin (g/dL) & $12.4(2.3)$ & $10.4(2.0)$ & $11.4(2.2)$ & $0.042^{\dagger}$ \\
\hline Haematocrit (\%) & $37.0(7.5)$ & $33.7(6.1)$ & $35.9(6.8)$ & 0.220 \\
\hline Platelet count $\left(10^{9} / \mathrm{L}\right)$ & $192.6(84.4)$ & $258.4(255.8)$ & $225.1(191.2)$ & 0.123 \\
\hline Sodium (mmol/L) & $138.0(9.7)$ & $137.3(5.1)$ & $137.7(7.9)$ & 0.708 \\
\hline Potassium (mmol/L) & $4.1(0.9)$ & $4.1(0.8)$ & $4.0(0.8)$ & 0.911 \\
\hline Urea $(\mathrm{mmol} / \mathrm{L})$ & $7.5(12.0)$ & $11.1(22.0)$ & $9.9(35.1)$ & 0.416 \\
\hline Creatinine $(\mu \mathrm{mol} / \mathrm{L})$ & $93.6(160.6)$ & $56.4(63.2)$ & $75.9(124.9)$ & 0.180 \\
\hline Total cholesterol $(\mathrm{mmol} / \mathrm{L})$ & $2.4(1.3)$ & $4.1(2.8)$ & $3.3(2.0)$ & 0.181 \\
\hline HDL cholesterol (mmol/L) & $0.5(0.2)$ & $0.6(0.3)$ & $0.5(0.2)$ & 0.667 \\
\hline LDL cholesterol (mmol/L) & $1.7(1.1)$ & $1.4(0.9)$ & $1.6(1.0)$ & 0.590 \\
\hline Triglycerides (mmol/L) & $1.2(0.7)$ & $1.1(0.5)$ & $1.2(0.6)$ & 0.779 \\
\hline Fasting blood glucose $(\mathrm{mmol} / \mathrm{L})$ & $9.4(9.4)$ & $10.6(7.8)$ & $10(8.3)$ & 0.643 \\
\hline $\mathrm{C}$-reactive protein $(\mathrm{nmol} / \mathrm{L})$ & $4647.6(4247.6)$ & $3695.2(4504.8)$ & $4133.3(4323.8)$ & 0.601 \\
\hline
\end{tabular}

electrocardiography. The mean haemoglobin concentration was lower in women than in men $(10.4 \mathrm{~g} / \mathrm{dL}$ v. $12.4 \mathrm{~g} / \mathrm{dL} ; p=0.042)$, while apparent differences in other biological characteristics did not reach statistical significance.

Table 3 summarises the echocardiographic findings. Compared with women, men had significant left ventricular (LV) systolic dysfunction: mean LV end-systolic diameter $47.3 \mathrm{~mm} \mathrm{v} .38 .6 \mathrm{~mm}$, $(p<0.01)$, mean LV ejection fraction 42.6 v. $51.5(p=0.01)$, and mean fractional shortening $21.4 \mathrm{~mm}$ v. $28.6 \mathrm{~mm}(p=0.01)$. Overall the mean RVSP was $55.6 \mathrm{mmHg}$ without gender difference. A borderline difference in the severity of mitral regurgitation was apparent between men and women $(p=0.070)$.

\section{Aetiology of pulmonary hypertension, severity grading and outcome}

Table 4 summarises subgroup classification of $\mathrm{PH}$, severity at presentation and outcome in a subset of patients. Overall, 78.5\% $(n=102)$ of the cohort had PH caused by left heart disease, which was similar in men and women $(81.3 \%$ v. $76.0 \%$; $p>0.05)$. Chronic thromboembolic $\mathrm{PH}$ was the least observed cause of $\mathrm{PH}$ in this study population (one patient). The majority (76.9\%) of patients had moderate or severe PH (RVSP $\geq 45 \mathrm{mmHg}$ ). No difference was found between men and women.

We recorded 29 deaths (20.3\%) and 15 readmissions (11.5\%) after a median follow-up of 60 days (interquartile range $30-150$ ). The in-hospital mortality rate was $18.5 \%$. Kaplan-Meier estimator (log rank 1.1; $p=0.30$ ) (Fig. 2) as well as age-adjusted Cox regression models did not show a significant difference in survival between men and women (hazard ratio 0.82 (95\% confidence interval 0.38 - 1.74); $p=0.601$ ) (Table 5).

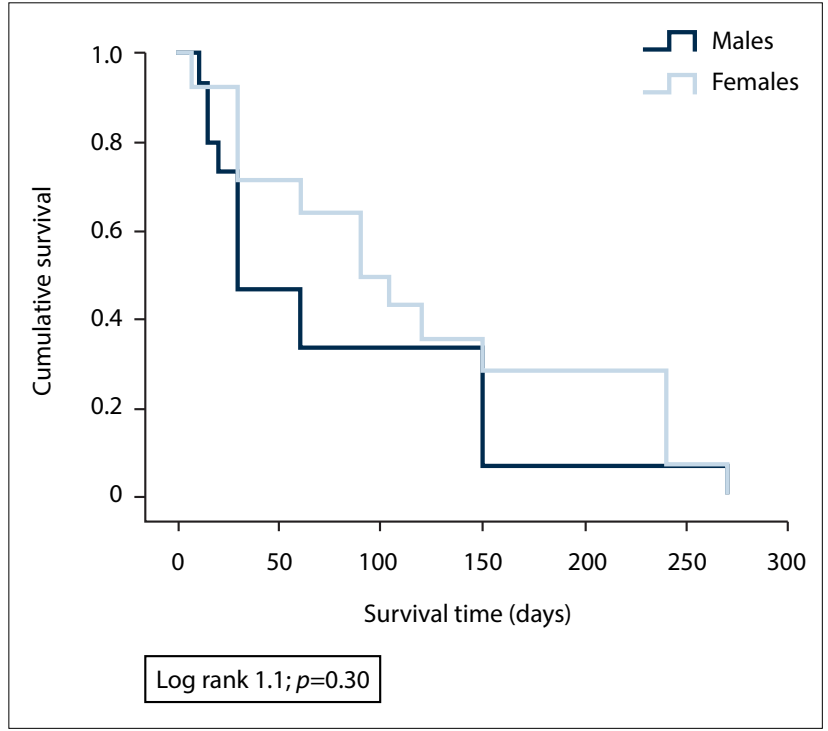

Fig. 2. Kaplan-Meier survival plot for mortality up to 12 months (360 days) comparing genders in patients with pulmonary hypertension in Douala, Cameroon, 2014.

\section{Discussion}

In this prospective cohort of patients with $\mathrm{PH}$ from specialised centres in Douala, Cameroon, a number of gender-related differences were observed. At baseline, men had smoking as a modifiable risk factor for CVD, while women had greater exposure to indoor cooking fumes. Both presented at advanced stages of the disease, men seeming more affected. Anaemia was more common in women, while 
Table 3. Baseline echocardiographic parameters of patients with pulmonary hypertension in Douala, Cameroon, 2014

\begin{tabular}{|c|c|c|c|c|}
\hline Variables & $\begin{array}{l}\text { Males } \\
(N=59)\end{array}$ & $\begin{array}{l}\text { Females } \\
(N=71)\end{array}$ & $\begin{array}{l}\text { Total } \\
(N=130)\end{array}$ & $p$-value ${ }^{*}$ \\
\hline \multicolumn{5}{|l|}{ Echocardiographic measurement, mean (SD) } \\
\hline Left atrial size $(\mathrm{mm})$ & $47.4(8.0)$ & $46.9(11.7)$ & $47.1(10.2)$ & 0.701 \\
\hline Left ventricular end-systolic diameter $(\mathrm{mm})$ & $47.3(16.1$ & $38.6(14.5)$ & $42.5(15.8)$ & $<0.01^{\dagger}$ \\
\hline Left ventricular end-diastolic diameter (mm) & $56.2(14.8)$ & $51.7(12.9)$ & $53.7(13.9)$ & 0.072 \\
\hline Left ventricular ejection fraction (\%) & $42.6(19.9)$ & $51.5(18.9)$ & $47.4(19.8)$ & $0.01^{\dagger}$ \\
\hline Fractional shortening $(\mathrm{mm})$ & $21.4(11.3)$ & $28.6(12.0)$ & $22.8(10.8)$ & $0.01^{\dagger}$ \\
\hline Interventricular septal diastolic diameter $(\mathrm{mm})$ & $12.1(2.9)$ & $10.6(2.6)$ & $11.3(2.8)$ & $<0.001^{+}$ \\
\hline Interventricular septal systolic diameter $(\mathrm{mm})$ & $14.3(3.6)$ & $14.2(4.7)$ & $14.3(4.2)$ & 0.988 \\
\hline Posterior wall diastolic diameter $(\mathrm{mm})$ & $12.1(4.5)$ & $10.7(2.9)$ & $11.3(3.8)$ & $0.030^{\dagger}$ \\
\hline Posterior wall systolic diameter (mm) & $14.7(4.0)$ & $14.2(3.3)$ & $14.5(3.6)$ & 0.521 \\
\hline RVSP (mmHg) & $53.6(14.9)$ & $57.3(16.5)$ & $55.6(15.8)$ & 0.168 \\
\hline TAPSE $(\mathrm{mm})$ & $18.1(6.2)$ & $19.3(6.4)$ & $18.7(6.3)$ & 0.541 \\
\hline \multicolumn{5}{|l|}{ Cardiac chamber and valvular evaluations, $n(\%)$} \\
\hline Right atrial dilatation & & & & 0.478 \\
\hline Mild & $11(18.6)$ & $14(19.7)$ & $25(19.2)$ & \\
\hline Moderate & $33(55.9)$ & $33(46.5)$ & $66(50.8)$ & \\
\hline Severe & $8(13.6)$ & $16(22.5)$ & $24(18.5)$ & \\
\hline Right ventricular dilatation & & & & 0.551 \\
\hline Mild & $18(30.5)$ & $21(29.6)$ & $39(30.0)$ & \\
\hline Moderate & $21(35.6)$ & $21(29.6)$ & $42(32.3)$ & \\
\hline Severe & $6(10.2)$ & $8(11.3)$ & $14(10.8)$ & \\
\hline Mitral regurgitation & & & & 0.070 \\
\hline Mild & $20(33.8)$ & $25(35.2)$ & $45(34.6)$ & \\
\hline Moderate & $19(32.2)$ & $12(16.9)$ & $31(23.8)$ & \\
\hline Severe & 0 & $4(5.6)$ & $4(3.1)$ & \\
\hline Mitral stenosis & & & & 0.302 \\
\hline Mild & 0 & 0 & 0 & \\
\hline Moderate & $1(1.7)$ & $2(2.8)$ & $3(2.3)$ & \\
\hline Severe & $1(1.7)$ & $5(7.0)$ & $6(4.6)$ & \\
\hline Aortic regurgitation & & & & 0.389 \\
\hline Mild & $13(22.0)$ & $12(16.9)$ & $25(19.2)$ & \\
\hline Moderate & $3(5.1)$ & $8(11.3)$ & $11(8.5)$ & \\
\hline Severe & 0 & 0 & 0 & \\
\hline Aortic stenosis & & & & 0.651 \\
\hline Mild & 0 & 0 & 0 & \\
\hline Moderate & 0 & $1(1.4)$ & $1(0.8)$ & \\
\hline Severe & $1(1.7)$ & $1(1.4)$ & $2(1.5)$ & \\
\hline Tricuspid regurgitation & & & & 0.376 \\
\hline Mild & $13(22.0)$ & $15(25.4)$ & $28(21.5)$ & \\
\hline Moderate & $39(66.1)$ & $39(54.9)$ & $78(60.0)$ & \\
\hline Severe & $6(10.2)$ & $15(21.1)$ & $21(16.2)$ & \\
\hline
\end{tabular}

echocardiographic LV systolic dysfunction was frequent in men. Left heart disease was the main cause of $\mathrm{PH}$ in the two groups, and survival rates were similar.

The overall mean age in our study was 58 years, which is two decades younger than in reports from most industrialised countries, ${ }^{[5]}$ but close to the 53 years reported in a recent study from Nigeria. ${ }^{[12]}$ Women in our study were older than men, which has also been reported among Caucasians. ${ }^{[20]}$ The mean age was, however, higher than that reported from a Portuguese $\mathrm{PH}$ registry. ${ }^{[21]}$ While relatively younger age appears to be a striking feature of our cohort of SSA patients with $\mathrm{PH}$, it should be noted that it is also a common finding in patients with HF, with relatively young patients being affected (median age 55 years). ${ }^{[22]}$ One likely explanation is the over-representation of group $2 \mathrm{PH}$ caused by left heart disease in our cohort, whether as a result of left HF or valvular heart disease, which usually occurs at a younger age.

The most frequent risk factors/comorbidities in the overall cohort were hypertension, diabetes, alcohol abuse and smoking. Alcohol abuse and active smoking were more common among men. This is similar to findings from the Registry to Evaluate Early and Long-Term Pulmonary Arterial Hypertension Disease Management (REVEAL) registry on pulmonary arterial hypertension in the USA, 
Table 4. Pulmonary hypertension subgroup classification, severity grading and outcome of patients with PH in Douala, Cameroon, 2014

\begin{tabular}{|c|c|c|c|c|}
\hline Variables & $\begin{array}{l}\text { Males } \\
(N=59)\end{array}$ & $\begin{array}{l}\text { Females } \\
(N=71)\end{array}$ & $\begin{array}{l}\text { Total } \\
(N=130)\end{array}$ & $p$-value ${ }^{*}$ \\
\hline Subgroup classification of $\mathrm{PH}, n(\%)$ & & & & 0.828 \\
\hline PAH (group 1) & $5(8.5)$ & $6(8.4)$ & $11(8.4)$ & \\
\hline PHLHD (group 2) & $48(81.3)$ & $54(76.0)$ & $102(78.5)$ & \\
\hline PHLD (group 3) & $3(5.1)$ & $4(5.6)$ & $7(5.4)$ & \\
\hline CTEPH (group 4) & 0 & $1(1.4)$ & $1(0.8)$ & \\
\hline Multifactorial (group 5) & $3(5.1)$ & $6(8.4)$ & $9(6.9)$ & \\
\hline Severity grading of $\mathrm{PH}, n(\%)$ & & & & 0.241 \\
\hline Mild PH (RVSP 36 - 44 mmHg) & $17(28.8)$ & $13(18.3)$ & $30(23.1)$ & \\
\hline Moderate PH (RVSP 45 - $59 \mathrm{mmHg}$ ) & $27(45.8)$ & $32(45.1)$ & $59(45.4)$ & \\
\hline Severe PH (RVSP $\geq 60 \mathrm{mmHg}$ ) & $15(25.4)$ & $26(36.6)$ & $41(31.5)$ & \\
\hline \multicolumn{5}{|l|}{ Outcome of $\mathrm{PH}$} \\
\hline Overall mortality, $n(\%)$ & $15(25.4)$ & $14(19.7)$ & $29(20.3)$ & 0.348 \\
\hline In-hospital mortality, $n(\%)$ & $14(23.7)$ & $10(14.1)$ & $24(18.5)$ & 0.211 \\
\hline $\begin{array}{l}\text { Overall time from presentation to death (days), } \\
\text { mean (SD, range) }\end{array}$ & $78.0(77.2,10-270)$ & $121.5(91.7,7-270)$ & $99.0(85.9,7-270)$ & 0.170 \\
\hline Overall time from presentation to death (days), median (IQR) ${ }^{\dagger}$ & $30(20-150)$ & $90(30-240)$ & $60(30-150)$ & 0.303 \\
\hline Overall re-hospitalisation rate through 360 days, $n(\%)$ & $6(10.2)$ & $9(12.6)$ & $15(11.5)$ & 0.670 \\
\hline All-cause 90 -day mortality, $n(\%)^{\dagger}$ & $10(16.9)$ & $7(9.9)$ & $17(13.1)$ & 0.122 \\
\hline All-cause 180 -day mortality, $n(\%)^{\dagger}$ & $14(23.7)$ & $10(14.1)$ & $24(18.5)$ & 0.901 \\
\hline All-cause 270 -day mortality, $n(\%)^{\dagger}$ & $15(25.4)$ & $14(19.7)$ & $29(22.3)$ & 0.303 \\
\hline All-cause 360 -day mortality, $n(\%)^{\dagger}$ & $15(25.4)$ & $14(19.7)$ & $29(22.3)$ & 0.303 \\
\hline
\end{tabular}

Table 5. Age-adjusted Cox regression analysis of the influence of age and gender on mortality among patients with pulmonary hypertension in Douala, Cameroon, 2014

\begin{tabular}{llllll}
\hline & \multicolumn{2}{c}{ Univariate analysis } & & \multicolumn{2}{c}{ Multivariate analysis } \\
\cline { 2 - 3 } \cline { 5 - 6 } Variables & HR $(\mathbf{9 5 \%} \mathbf{C I})$ & $\boldsymbol{p}$-value & & HR $(\mathbf{9 5 \%} \mathbf{C I})$ & $\boldsymbol{p}$-value \\
\hline Age & $0.98(0.95-1.00)$ & 0.061 & & $0.98(0.96-1.00)$ & 0.081 \\
Gender & $0.72(0.34-1.51)$ & 0.383 & & $0.82(0.38-1.74)$ & 0.601 \\
HR = hazard ratio; $\mathrm{CI}=$ confidence interval. & & &
\end{tabular}

where hypertension was a frequent comorbidity. ${ }^{[23]}$ Similarly, a cross-sectional survey in Tanzania recently highlighted the fact that women had a $50 \%$ lower odds of hypertension compared with men. The slight predominance of conventional modifiable risk factors for CVD among men in this cohort is similar to findings among patients with HF in Africa, ${ }^{[19]}$ but is contrary to reports from the EuroHeart Failure Survey ${ }^{[24]}$ The finding of hypertension as the most frequent CVD risk factor in our cohort is unsurprising, as over three-quarters of the patients had group $2 \mathrm{PH}$ caused by left heart disease, which in our setting is frequently hypertensive heart disease with a final progression to left HF. ${ }^{[22.25]}$ Exposure to indoor cooking fumes, especially from burning wood, was significantly more frequent among women. It is common for women in Africa to cook over an open fireplace, particularly in rural settings. However, this is not the case in middle- and high-income countries. The contribution of this exposure to the occurrence, severity and outcome of $\mathrm{PH}$ in African women still needs to be explored, and group $3 \mathrm{PH}$, caused by chronic lung disease, more intensively investigated. However, this requires additional equipment such as high-resolution computed tomography and lung function testing. Among the risk factors for chronic lung disease, a history of previous TB infection was also significantly more common in women than in men in our cohort. Unfortunately, the relationship to HIV infection (with a higher incidence of TB in HIV-infected individuals) could not be investigated, because HIV testing is not performed as a standard test in cardiac patients in Cameroon. Also, women were generally more obese than men and, although obesity has been independently associated with $\mathrm{PH}$, this finding could simply reflect the high prevalence of female obesity in our population. ${ }^{[26]}$ The reasons for some of our findings are unclear, but it remains possible that exposure of women to $\mathrm{PH}$ risk factors in our setting may be more complex and multifactorial than that of men, owing to a combination of the above risk factors (chronic lung disease and HIV) in varying degrees.

The majority of our patients, particularly men, presented at advanced stage of the disease (NYHA III/IV). This is similar to reports from Nigeria, ${ }^{[12]}$ Australia ${ }^{[5]}$ and Portugal, ${ }^{[21]}$ where most patients present with features of advanced HF. This late presentation is probably due to nonspecific symptoms of $\mathrm{PH}$ in the early stages, as well as limited availability of diagnostic tools. Anaemia was observed more often in women than in men. Similar observations were made in The sub-Saharan Africa Survey of Heart Failure (THESUS-HF) registry, probably related to menstruation. ${ }^{[19]}$

Atrial fibrillation, sinus tachycardia and LV hypertrophy were the main electrocardiographic abnormalities in our cohort. Although previous reports and clinical guidelines suggest that patients with $\mathrm{PH}$ have RV hypertrophy on electrocardiograms, ${ }^{[2,27]}$ this was not the case in our cohort, probably owing to the high prevalence of hypertension, LV dysfunction leading to LV hypertrophy; this consequently increases the left atrial pressure and may predispose to arrhythmias such as atrial fibrillation. ${ }^{[22,25]}$ Supraventricular 
arrhythmias such as atrial fibrillation are, however, said to occur in advanced stages of $\mathrm{PH}$ and are associated with clinical deterioration, ${ }^{[28]}$ which probably explains the high case fatality in our cohort. On echocardiography, men had significant LV systolic dysfunction compared with women. With hypertension generally being more prevalent in men, it is likely that the observed LV dysfunction in men was due to hypertensive heart disease (as the hypertrophy as seen on the electrocardiogram). In contrast is the observation of a lower mean systolic blood pressure in men, which could potentially reflect advanced LV dysfunction and HF. Mitral valve lesions (stenosis and regurgitation) were frequent among women, with aortic lesions being more common in men. This is fairly consistent with the high prevalence of rheumatic heart disease in $\mathrm{SSA}^{[29]}$ and its previously reported predominance in female HF patients in the region. ${ }^{[19]}$ Although no significant gender difference in survival was observed, the high mortality rate from $\mathrm{PH}$ in this setting is worrying. Doctors in the region should have a high index of suspicion, and screening tools need to be put in place.

\section{Study limitations and strengths}

This study had a number of limitations. First, echocardiography was the main diagnostic tool used for the diagnosis of $\mathrm{PH}$, as opposed to gold-standard RHC. This limitation of our registry has been discussed previously ${ }^{[14]}$ and has to do with the challenges of diagnosing $\mathrm{PH}$ in the resource-limited settings that are so common in SSA. Echocardiography is much more affordable and available, and poses almost no risk compared with the invasive procedure of RHC. ${ }^{[30]}$ Furthermore, the diagnostic accuracy of echocardiography has been reported in a meta-analysis and it is now widely recognised as a screening tool for $\mathrm{PH}^{[31]}$ The study was also conducted in specialised referral cardiovascular centres, and we acknowledge that patients who could not afford these services could have been missed; interpretation and generalisability of our results are therefore limited, as they probably represent findings from the participating centres. The small sample size may also limit the generalisability of our observations and disparities between genders, especially in respect of mortality and hospitalisation.

Our study nevertheless has merit in that it is among the few studies that have attempted to explore gender differences in epidemiology, clinical characteristics and echocardiographic features of patients with $\mathrm{PH}$ in a resource-limited setting. The prospective design also gives strength to the results obtained, and as an echocardiographic study it can be compared with many other studies worldwide that have used the same diagnostic modality. Our findings are relevant for both clinicians and public health experts, as they provided data on baseline clinical characteristics of $\mathrm{PH}$ as well as on potential risk factors. Clinicians should increase their index of suspicion, and public health experts should plan for risk factor interventions and allocation of resources.

\section{Conclusion}

Gender differences in risk factors and comorbidities of patients with $\mathrm{PH}$ in Africa exist, with modifiable cardiovascular risk factors in men as opposed to valvular heart disease in women. Interventions for the control of $\mathrm{PH}$ in men should target cardiovascular risk factors such as hypertension, alcohol abuse and smoking, while those for women should be directed towards chronic lung disease and rheumatic heart disease, as well as hypertension. Mortality from $\mathrm{PH}$ in our cohort was high, and there is a need for larger multicentre studies to confirm our findings as well as to explore further gender-related differences in $\mathrm{PH}$ in Africa. The different baseline characteristics observed could potentially reveal different pathogeneses of $\mathrm{PH}$ in men and women in our setting, which need further investigation.

Acknowledgements. We are grateful to the patients who participated in this study, and the management and staff of the study centres for authorising and collaborating with it.

Author contributions. LNA, AD, FT, KS and APK conceived and designed the study; LNA, AD, JN, SM, XK, FK, BHMN and M-SD contributed to data acquisition; LNA and APK did statistical analysis and interpretation; LNA drafted the initial manuscript; and APK, AD, KS, KBN and FT critically revised the manuscript. All authors read and approved the final manuscript.

Funding. None.

Conflicts of interest. None.

1. Fang JC, DeMarco T, Givertz MM, et al. World Health Organization pulmonary hypertension group 2: Pulmonary hypertension due to left heart disease in the adult - a summary statement from the Pulmonary Hypertension Council of the International Society for Heart and Lung Transplantation. J Pulmonary Hypertension Council of the International Society for Heart and Lung Trans

Heart Lung Transplant 2012;31(9):913-933. https://doi.org/10.1016/j.healun.2012.06.002
2. Galiè N, Hoeper MM, Humbert M, et al., Task Force for the Diagnosis and Treatment of Pulmonary

. Galiè N, Hoeper MM, Humbert M, et al., Task Force for the Diagnosis and Treatment of Pulmonary
Hypertension of the European Society of Cardiology (ESC) and the European Respiratory Society Hypertension of the European Society of Cardiology (ESC) and the European Respiratory Society
(ERS) endorsed by the International Society of Heart and Lung Transplantation (ISHLT). Guidelines for the diagnosis and treatment of pulmonary hypertension. Eur Respir J 2009;34(6):1219-1263. https://doi.org/10.1183/09031936.00139009

3. Simonneau G, Gatzoulis MA, Adatia I, et al. Updated clinical classification of pulmonary hypertension. J Am Coll Cardiol 2013;62(25 Suppl):D34-D41. https://doi.org/10.1016/j.jacc.2013.10.029

4. Todd NW, Lavania S, Park MH, et al. Variable prevalence of pulmonary hypertension in patients with advanced interstitial pneumonia. J Heart Lung Transplant 2010;29(2):188-194. https://doi org/10.1016/j.healun.2009.07.025

5. Strange G, Playford D, Stewart S, et al. Pulmonary hypertension: Prevalence and mortality in the Armadale echocardiography cohort. Heart 2012;98(24):1805-1811. https://doi.org/10.1136 heartinl-2012-301992

6. Thienemann F, Sliwa K, Rockstroh JK. HIV and the heart: the impact of antiretroviral therapy: A global perspective. Eur Heart J 2013;34(46):3538-3546. https://doi.org/10.1093/eurheart//eht388

Dzudie A, Kengne AP, Thienemann F, Sliwa K. Predictors of hospitalisations for heart failure and Dzudie A, Kengne AP, Thienemann F, Sliwa K. Predictors of hospitalisations for heart failure and
mortality in patients with pulmonary hypertension associated with left heart disease: A systematic mortality in patients with pulmonary hypertension associated with left heart diseas
review. BMJ Open 2014;4(7):e004843. https://doi.org/10.1136/bmjopen-2014-004843

review. BMJ Open 2014;4(7):e004843. https://doi.org/10.1136/bmjopen-2014-004843
8. Mocumbi AO, Thienemann F, Sliwa K. A global perspective on the epidemiology of pulmonary hypertension. Can J Cardiol 2015;31(4):375-381. https://doi.org/10.1016/j.cjca.2015.01.030

9. Szwejkowski BR, Elder DHJ, Shearer F, et al. Pulmonary hypertension predicts all-cause mortality in patients with heart failure: A retrospective cohort study. Eur J Heart Fail 2012;14(2):162-167. https:// doi.org/10.1093/eurjhf/hfr159

10. Enriquez-Sarano M, Rossi A, Seward JB, Bailey KR, Tajik AJ. Determinants of pulmonary hypertension in left ventricular dysfunction. J Am Coll Cardiol 1997;29(1):153-159. https://doi.org/10.1016/S07351097(96)00436-6

11. Lam CSP, Roger VL, Rodeheffer RJ, Borlaug BA, Enders FT, Redfield MM. Pulmonary hypertension in heart failure with preserved ejection fraction: A community-based study. J Am Coll Cardiol 2009;53(13):1119-1126. https://doi.org/10.1016/j.jacc.2008.11.051

12. Karaye KM, Saidu H, Bala MS, Yahaya IA. Prevalence, clinical characteristics and outcome of pulmonary hypertension among admitted heart failure patients. Ann Afr Med 2013;12(4):197-204. pulmonary hypertension among admitted
https://doi.org/10.4103/1596-3519.122685

13. Steenekamp JH, Simson IW, Theron W. Cardiovascular causes of death at Tshepong Hospital in 1 year 1989 - 1990: A necropsy study. S Afr Med J 1992;81(3):142-146.

14. Thienemann F, Dzudie A, Mocumbi AO, et al. Rationale and design of the Pan African Pulmonary Hypertension Cohort (PAPUCO) study: Implementing a contemporary registry on pulmonar hypertension in Africa. BMJ Open 2014;4(10):e005950. https://doi.org/10.1136/bmjopen-2014-005950

15. Thienemann F, Dzudie A, Mocumbi AO, et al. The causes, treatment, and outcome of pulmonar hypertension in Africa: Insights from the Pan African Pulmonary Hypertension Cohort (PAPUCO) Registry. Int J Cardiol 2016;221:205-211. https://doi.org/10.1016/j.ijcard.2016.06.242

16. Smilde TDJ, Damman K, van der Harst P, et al. Differential associations between renal function and 'modifiable' risk factors in patients with chronic heart failure. Clin Res Cardiol 2009;98(2):121-129. https://doi.org/10.1007/s00392-008-0732-z

17. Tsuchihashi-Makaya M, Hamaguchi S, Kinugawa S, et al. Sex differences with respect to clinical characteristics, treatment, and long-term outcomes in patients with heart failure. Int J Cardiol 2011;150(3):338-339. https://doi.org/10.1016/.ijcard.2011.03.042

18. Brandsaeter B, Atar D, Agewall S, Norwegian Heart Failure Registry. Gender differences among Brandsaeter B, Atar D, Agewall S, Norwegian Heart Failure Registry. Gender differences among
Norwegian patients with heart failure. Int J Cardiol 2011;146(3):354-358. https://doi.org/10.1016/j. Norwegian patients
ijcard.2009.07.014

19. Ogah OS, Davison BA, Sliwa K, et al. Gender differences in clinical characteristics and outcome of acute heart failure in sub-Saharan Africa: Results of the THESUS-HF study. Clin Res Cardiol 2015;104(6):481-490. https://doi.org/10.1007/s00392-015-0810-y

20. Peacock AJ, Murphy NF, McMurray JJV, Caballero L, Stewart S. An epidemiological study of pulmonary arterial hypertension. Eur Respir J 2007;30(1):104-109. https://doi.org/10.1183/09031936.00092306

1. Baptista R, Meireles J, Agapito A, et al. Pulmonary hypertension in Portugal: First data from nationwide registry. Biomed Res Int 2013;2013:489574. https://doi.org/10.1155/2013/489574

22. Damasceno A, Mayosi BM, Sani M, et al. The causes, treatment, and outcome of acute heart failure in 1006 Africans from 9 countries. Arch Intern Med 2012;172(18):1386-1394. https://doi.org/10.1001/ archinternmed.2012.3310

23. Benza RL, Miller DP, Gomberg-Maitland M, et al. Predicting survival in pulmonary arterial hypertension: Insights from the Registry to Evaluate Early and Long-Term Pulmonary Arterial hypertension: Insights from the Registry to Evaluate Early and Long-Term Pulmonary Arterial
Hypertension Disease Management (REVEAL). Circulation 2010;122(2):164-172. https://doi. Hypertension Disease Management (REVEAL

24. Nieminen MS, Harjola V-P, Hochadel M, et al. Gender related differences in patients presenting with 24. Nieminen MS, Harjola V-P, Hochadel M, et al. Gender related differences in patients presenting with
acute heart failure: Results from EuroHeart Failure Survey II. Eur J Heart Fail 2008;10(2):140-148. https://doi.org/10.1016/j.ejheart.2007.12.012 
25. Dzudie A, Kengne AP, Muna WFT, et al. Prevalence, awareness, treatment and control of hypertension in a self-selected sub-Saharan African urban population: A cross-sectional study. BMJ Open 2012;2(4). in a self-selected sub-Saharan African urban pop

26. Mandengue SH, Bita Fouda AA, Epacka Ewane M, Moumbe Tamba S, Kollo B. Epidemiology of obesity among students in Douala, Cameroon. Med Sante Trop 2015;25(4):386-391. https://doi. obesity among students in
org $/ 10.1684 / \mathrm{mst} .2015 .0523$

27. Nauser TD, Stites SW. Diagnosis and treatment of pulmonary hypertension. Am Fam Physician 2001;63(9):1789-1798.

28. Tongers J, Schwerdtfeger B, Klein G, et al. Incidence and clinical relevance of supraventricular tachyarrhythmias in pulmonary hypertension. Am Heart J 2007;153(1):127-132. https://doi org/10.1016/j.ahj.2006.09.008

29. Mayosi BM. The challenge of silent rheumatic heart disease. Lancet Glob Health 2014;2(12):e677-e678 http://dx.doi.org/10.1016/S2214-109X(14)70331-6
30. Khush KK, Tasissa G, Butler J, McGlothlin D, de Marco T, ESCAPE Investigators. Effect of pulmonary hypertension on clinical outcomes in advanced heart failure: Analysis of the Evaluation Study of Congestive Heart Failure and Pulmonary Artery Catheterization Effectiveness (ESCAPE) database. Am Heart J 2009;157(6):1026-1034. https://doi.org/10.1016/j.ahj.2009.02.022

31. Janda S, Shahidi N, Gin K, Swiston J. Diagnostic accuracy of echocardiography for pulmonary hypertension: A systematic review and meta-analysis. Heart 2011;97(8):612-622. https://doi. org/10.1016/j.ahj.2009.02.022

Accepted 6 April 2017 